\title{
Implementasi Algoritma Clustering K-Means Untuk Mengelompokkan Mahasiswa Baru Yang Berpotensi (Studi Kasus: Stmik Budi Darma)
}

\author{
Efori Buulolo ${ }^{1}$, Rian Syahputra ${ }^{2}$ \\ STMIK Budi Darma ${ }^{1,2}$ \\ Jl. Sisingamangara No.338 Sp. Limun Medan, 0617875998 \\ buuloloefori21@gmail.com¹, ryansyah93@gmail.com²
}

\begin{abstract}
Every year STMIK Budi Darma accepts new students through the selection test path. The process of student admission at STMIK Budi Darma begins with socialization to the community or school, registration, selection examinations, announcement of exam results, Re-registration, Campus Recognition System (CRS) and the lecture process. The value of the selection test results, the average National exam score, the mathematics National exam scores and the English National exam scores are combined and used in ranking prospective students who are accepted based on the capacity of the study program. So far, STMIK Budi Darma lecturers sometimes find it difficult to carry out classroom actions because each student has unequal potential so the learning outcomes are not optimal. One of them is caused by grouping new students into one class based on ranking, not based on the potential of each new student. In order to group prospective new students based on their potential, $K$ Means clustering algorithm is used. The basis of grouping with the K-Means clustering algorithm is based on the closest distance values of numerically based criteria with output in the form of clusters. The cluster that has been formed is used as the basis for grouping new students into one class.
\end{abstract}

Keywords: Grouping, K-Means, students, new, potential

Abstrak- Setiap tahun STMIK Budi Darma menerima mahasiswa baru melalui jalur ujian seleksi. Proses penerimaan mahasiswa di STMIK Budi Darma diawali dengan sosialisasi kepada masyarakat atau sekolah, pendaftaran, ujian seleksi, pengumuman hasil ujian, Registrasi Ulang, Sistem Pengenalan Kampus (SPK) dan proses perkuliahan. Nilai hasil ujian seleksi, nilai UN rata-rata, nilai UN matematika dan nilai UN bahasa Inggris digabung dan digunakan dalam perangkingan calon mahasiswa yang diterima berdasarkan daya tampung program studi. Selama ini dosen STMIK Budi Darma kadang kesulitan melaksanakan tindakan kelas dikarenakan setiap mahasiswa mempunyai potensi yang tidak sama sehingga hasil pembelajaran tidak maksimal. Hal tersebut salah satunya disebabkan pengelompokan mahasiswa baru kedalam satu kelas berdasarkan perangkingan, bukan berdasarkan potensi setiap mahasiswa baru. Agar pengelompokan calon mahasiswa baru berdasarkan potensi yang dimiliki maka digunakan algoritma clustering K-Means. Dasar pengelompokan dengan algoritma clustering K-Means berdasarkan nilai jarak terdekat dari kriteria yang berbasis numerik dengan output dalam bentuk cluster. Cluster yang telah dibentuk digunakan sebagai dasar pengelompokan calon mahasiswa baru kedalam satu kelas.

Kata kunci: Pengelompokan, K-Means, mahasiswa, baru, potensi

\section{PENDAHULUAN}

STMIK Budi Darma merupakan salah Perguruan Tinggi Swasta yang ada di kota Medan Sumatera Utara dengan mengolah 2(dua) program studi yaitu Teknik 
Informatika (S1) dan Manajemen Informatika (D3). Mendekati akhir tahun ajaran dan awal tahun ajaran setiap tahunnya STMIK Budi Darma melaksanakan penerimaan mahasiswa baru. Proses penerimaan mahasiswa baru di STMIK Budi Darma yaitu sosialisasi kepada masyarakat/sekolah, pendaftaran, ujian seleksi, pengumuman hasil seleksi, Registrasi ulang, Sistem Pengenalan Kampus (SPK) dan perkuliahan. Materi yang diuji untuk seleksi adalah pengetahuan umum, matematika, Bahasa inggris dan pengetahuan komputer. Hasil dari ujian tersebut digabung dengan nilai dari nilai UN (Ujian Nasional) rata-rata, nilai UN Matematika dan nilai UN Bahasa Inggris. Nilai yang telah digabung akan digunakan untuk proses perangkingan calon mahasisiswa baru yang diterima sesuai dengan daya tampung masing-masing program studi yang ada di STMIK Budi Darma. Proses penerimaan mahasiswa baru tersebut telah memberikan input yang baik terhadap STMIK Budi Darma dibuktikan dengan meningkatnya kualitas mahasiswa dan lulusan STMIK Budi Darma.

Selama ini dosen pengajar matakuliah di STMIK Budi Darma kadang mengalami kesulitan dalam melaksanakan tindakan kelas, hal tersebut disebabkan potensi kemampuan yang dimiliki oleh setiap mahasiswa tidak sama seperti dalam satu kelas sebagian mahasiswa berpotensi dalam bidang eksakta tetapi kurang berpotensi berbahasa Inggris dan sebaliknya, sebagian mahasiswa berpotensi dalam berbahasa Inggris tetapi kurang berpotensi dalam bidang eksakta akibatnya hasil pembelajaran tidak maksimal. Salah satu penyebab terjadinya hal seperti itu adalah karena pengelompokan mahasiswa baru tidak didasarkan potensi yang dimiliki oleh setiap mahasiswa tetapi berdasarkan perangkingan seperti rangking 1 sampai 30 Kelas A, rangking 31 sampai 60 Kelas B, dan seterusnya. Untuk mengatasi masalah tersebut diatas, diperlukan algoritma pengelompokan mahasiswa berdasarkan potensi yang dimiliki. Algoritma Clustering K-Means merupakan salah satu algoritma dalam data mining yang berbasis jarak terpendek yang membagi data kedalam beberapa cluster berdasarkan kriteria yang berbasis numerik. Cluster yang terbentuk dapat digunakan sebagai pengelompokan mahasiswa baru berdasarkan potensi yang dimiliki oleh setiap mahasiswa[1][2].

\section{METODOLOGI PENELITIAN}

Untuk tahapan yang dilakukan pada penelitian ini adalah sebagai berikut:

\begin{tabular}{|l|l|l|l|l|}
\hline \multicolumn{1}{|c|}{ Pra Penelitian } & Tahapan Data Mining & \multicolumn{1}{|c|}{ K-Means } & Presentation & Results \\
\hline $\begin{array}{l}\text { Studi Pendahuluan } \\
\text { Pengumpulan Data } \\
\text { Studi Pustaka }\end{array}$ & $\begin{array}{l}\text { Data Cleaning } \\
\text { Data Integration } \\
\text { Data Selection } \\
\text { Data Transformation }\end{array}$ & $\begin{array}{l}\text { Inisialisasi centroid } \\
\text { Menghitung Cluster } \\
\text { Hitung Jarak } \\
\text { Pengelompokan }\end{array}$ & $\begin{array}{l}\text { Pengelompokan } \\
\text { Mahasiswa baru } \\
\text { berdasarkan } \\
\text { potensi }\end{array}$ \\
\hline
\end{tabular}

Gambar 1. Alur penelitian

\subsection{Pra Penelitian}

a. Untuk studi pendahuluan dimulai dengan melaksanakan pengamatan terhadap hasil ujian seleksi masuk STMIK Budi Darma dan interview terhadap dosen pengajar dan mahasiswa untuk mengetahui kendala yang dihadapi selama ini 
yang berkaitan dengan tindakan kelas dan mengkorelasikan dengan hasil pembelajaran setiap mahasiswa.

b. Setelah mengetahui permasalahan, penulis memperoleh data calon mahasiswa baru yang mengikuti ujian seleksi. data yang diperoleh berupa nama calon mahasiswa serta hasil ujian seleksi dan hasil UN dan USBN (Ujian Sekolah Bersandar Nasional). Nilai hasil ujian seleksi dan nilai UN serta USBN dibagi menjadi 3(tiga) attribute sesuai dengan potensi calon mahasiswa yaitu eksakta, Bahasa dan Umum. Nilai eksakta diperoleh dari gabungan nilai UN dan hasil ujian yang berbasis eksakta seperti matematika dan mata pelajaran jurusan. Nilai bahasa diperoleh dari nilai UN dan hasil ujian seleksi yang berbasis bahasa seperti bahasa Indonesia dan bahasa inggris, nilai umum diperoleh dari gabungan nilai UN/USBM dan hasil ujian seleksi yang berbasis umum seperti pengetahuan umum, PPKN, sejarah umum dan lain-lain.

c. Kegiatan selanjutanya yaitu pencarian referensi yang berkaitan dengan topik pembahasan dan algoritma yang digunakan. Referensi yang digunakan berupa buku, $e$-book, jurnal untuk mengetahui teori dan solusi terhadap permasalahan.

\subsection{Tahapan Data Mining}

Agar data yang digunakan berkualitas, maka data yang digunakan untuk pengelompokan mahasiswa baru harus melalui tahapan data mining. Adapun tahapan tersebut adalah:

a. Cleaning: Proses membersikan data dari noise, hilang atau tidak konsisten

b. Integration: Proses menggabungkan data seperti menggabung nilai materi ujian kedalam 3(tiga) attribute yaitu eksakta, Bahasa dan Umum.

c. Selection: Proses pengambingan sampling data dari beberapa data yang dapat merepresentasikan data yang sebenarya.

d. Transformation: Perubahan format data. Data pengelompokan mahasiswa berpotensi, data yang digunakan di lengkapi beberapa attribute[3][4]. 


\subsection{Algoritma K-Means}

Berikut adalah proses data mining algoritma clustering K-Means:

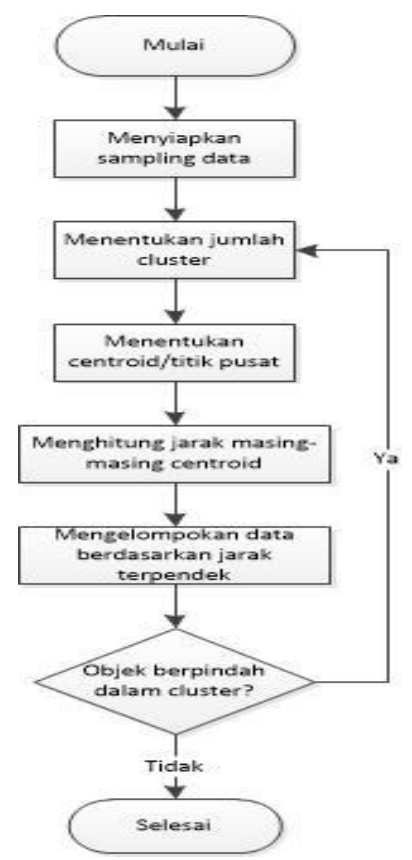

Gambar 2. Diagram alir algoritma K-Means

Berdasarkan diagram alir pada gambar 2 menunjukan langkah-langkah algoritma KMeans sebagai berikut:

1. Menentukan dan menyiapkan sejumlah data yang digunakan sebagai sampling data.

2. Menentukan jumlah cluster.

3. Menentukan centroid/titik pusat data secara acak.

4. Menentukan jarak masing-masing centroid berdasarkan jarak terpendek dengan menggunakan model Euclidean yang dirumuskan sebagai berikut:

$d_{i j}=\sqrt{\left(x_{1 i}-x_{1 j}\right)^{2}}+\left(x_{2 i}-x_{2 j}\right)^{2}+\cdots+\left(x_{k i}-x_{k j}\right)^{2}$

Keterangan:

$d_{i j}=$ Jarak dari data ke i ke pusat cluster $\mathrm{j}$

$x_{k i}=$ Dari dari ke $-\mathrm{i}$ pada attribute data ke $-\mathrm{k}$

$x_{k j}=$ Dari dari ke $-\mathrm{j}$ pada attribute data ke $-\mathrm{k}$

5. Setelah memperoleh nilai cluster untuk setiap nilai, maka dilakukan pencarian nilai rata-rata masing-masing cluster dengan menjumlahkan nilai anggota masing-masing cluster.

6. Dari nilai rata-rata centroid dilakukan perhitungan jarak dari keanggotaan yang baru. Jika pusat cluster berubah maka diulangi lagi proses 4 dan jika tidak maka proses selesai[5][6]. 


\subsection{Presentation}

Setelah implementasi algoritma Clustering K-Means diperoleh pengetahuan/knowledge yang dapat dipresentasikan untuk digunakan dalam mengelompokkan mahasiswa baru yang berpotensi.

\subsection{Results}

Pengelompokan mahasiswa baru sesuai dengan potensi yang dimiliki oleh setiap mahasisiwa baru dalam satu kelas merupakan hasil dari penelitian ini.

\section{HASIL DAN PEMBAHASAN}

Untuk dapat mengelompokan calon mahasiswa baru berdasarkan potensi yang dimilikinya maka digunakan data calon mahasiswa baru yang telah mengikuti ujian seleksi masuk STMIK Budi Darma. Jumlah data yang digunakan untuk sampling adalah 15 calon mahasiswa baru, dan dapat dilihat pada Tabel 1.

Tabel 1. Sampling Data

\begin{tabular}{|r|l|c|c|c|}
\hline No. & \multicolumn{1}{|c|}{ Nama } & Eksakta & Bahasa & Umum \\
\hline 1 & Dwiki Fahizurrahman & 75 & 78 & 74 \\
\hline 2 & Jhonswardi Sianturi & 80 & 90 & 65 \\
\hline 3 & Chairina Ridwan & 65 & 65 & 63 \\
\hline 4 & Anisa Suryani Rangkuti & 83 & 78 & 77 \\
\hline 5 & Habib Nasrullah Fisyih & 76 & 89 & 89 \\
\hline 6 & Ridho Adrian & 56 & 65 & 76 \\
\hline 7 & Yantonius Gulo & 89 & 55 & 45 \\
\hline 8 & Wijaya Avin Mandela Gea & 50 & 78 & 76 \\
\hline 9 & Nurkhofifah Nasution & 67 & 87 & 88 \\
\hline 10 & Mita Dewi Yanti Siregar & 82 & 91 & 65 \\
\hline 11 & Kartika & 78 & 67 & 65 \\
\hline 12 & Mario Valentino Batu Bara & 66 & 51 & 78 \\
\hline 13 & Boy Alfredo Silaban & 59 & 67 & 56 \\
\hline 14 & Suhaidi & 68 & 53 & 67 \\
\hline 15 & Muammar Nugraha Rozy Affan & 78 & 78 & 89 \\
\hline
\end{tabular}

Data pada Tabel 1, digunakan untuk pengelompokan potensi calon mahasiswa baru dengan algoritma Clustering K-Means.

\section{Iterasi - 1:}

Penentuan nilai Centroid/titik pusat awal yang digunakan dalam penelitian ini diambil dari sampling data secara acak, sebagai berikut:

Tabel 2. Centroid/Titik Pusat Awal

\begin{tabular}{|c|c|c|c|c|c|}
\hline No & Nama Calon Mahasiswa & Eksakta & Bahasa & Umum & Cn \\
\hline 8 & Wijaya Avin Mandela Gea & 50 & 78 & 76 & C1 \\
\hline 6 & Ridho Adrian & 67 & 87 & 88 & C2 \\
\hline 13 & Boy Alfredo Silaban & 59 & 67 & 56 & C3 \\
\hline
\end{tabular}


Adapun hasil perhitungan jarak dengan model Euclidean adalah sebagai berikut:

Tabel 3. Hasil perhitungan jarak

\begin{tabular}{|r|l|c|c|c|c|}
\hline No. & Nama Calon Mahasiswa & dc1 & dc2 & dc3 & Hasil \\
\hline 1 & Dwiki Fahizurrahman & 25.080 & 18.466 & 26.476 & $\mathbf{2}$ \\
\hline 2 & Jhonswardi Sianturi & 34.132 & 26.589 & 32.419 & $\mathbf{2}$ \\
\hline 3 & Chairina Ridwan & 23.728 & 33.362 & 9.434 & $\mathbf{3}$ \\
\hline 4 & Anisa Suryani Rangkuti & 33.015 & 21.401 & 33.734 & $\mathbf{2}$ \\
\hline 5 & Habib Nasrullah Fisyih & 31.081 & 9.274 & 43.151 & $\mathbf{2}$ \\
\hline 6 & Ridho Adrian & 14.318 & 27.368 & 20.322 & $\mathbf{1}$ \\
\hline 7 & Yantonius Gulo & 54.873 & 57.940 & 34.132 & $\mathbf{3}$ \\
\hline 8 & Wijaya Avin Mandela Gea & 0.000 & 22.672 & 24.536 & $\mathbf{1}$ \\
\hline 9 & Nurkhofifah Nasution & 22.672 & 0.000 & 38.575 & $\mathbf{2}$ \\
\hline 10 & Mita Dewi Yanti Siregar & 36.249 & 27.749 & 34.438 & $\mathbf{2}$ \\
\hline 11 & Kartika & 32.031 & 32.404 & 21.024 & $\mathbf{3}$ \\
\hline 12 & Mario Valentino Batu Bara & 31.448 & 37.376 & 28.089 & $\mathbf{3}$ \\
\hline 13 & Boy Alfredo Silaban & 24.536 & 38.575 & 0.000 & $\mathbf{3}$ \\
\hline 14 & Suhaidi & 32.094 & 39.975 & 19.950 & $\mathbf{3}$ \\
\hline 15 & Muammar Nugraha Rozy Affan & 30.871 & 14.248 & 39.636 & $\mathbf{2}$ \\
\hline
\end{tabular}

Hasil pengelompokan didasarkan pada jarak terpendek, jika dc1<dc2 dan dc1 $<$ dc3, maka termasuk dalam cluster 1 , jika dc $2<\mathrm{dc} 1$ dan dc $2<\mathrm{dc} 3$, maka termasuk kedalam cluster 2 , dan jika dc3 $<$ dc1 dan dc3<dc2 maka termasuk kedalam cluster 3.

\section{Iterasi - 2:}

Pencarian nilai centroid/titik pusat awal pada iterasi -2 diperolah dari nilai rata-rata penjumlahan anggota masing-masing cluster, setelah itu dibagi dengan jumlah anggota masing-masing cluster.

Tabel 4. Centroid / Titik Pusat Awal di Iteransi - 2

\begin{tabular}{|l|l|l|l|}
\hline 53.000 & 71.500 & 76.000 & C1 \\
\hline 77.286 & 84.429 & 78.143 & C2 \\
\hline 67.200 & 60.600 & 65.800 & C3 \\
\hline
\end{tabular}

Adapun hasil perhitungan jarak pada iterasi - 2 dengan model Euclidean adalah sebagai berikut:

Tabel 5. Hasil Perhitungan Jarak pada iterasi -2

\begin{tabular}{|c|l|c|c|c|c|}
\hline No & Nama Calon Mahasiswa & dc1 & dc2 & Dc3 & Hasil \\
\hline 1 & Dwiki Fahizurrahman & 23.027 & 7.982 & 20.757 & $\mathbf{2}$ \\
\hline 2 & Jhonswardi Sianturi & 34.529 & 14.531 & 32.076 & $\mathbf{2}$ \\
\hline 3 & Chairina Ridwan & 18.848 & 27.527 & 5.660 & $\mathbf{3}$ \\
\hline 4 & Anisa Suryani Rangkuti & 30.712 & 8.677 & 26.035 & $\mathbf{2}$ \\
\hline 5 & Habib Nasrullah Fisyih & 31.690 & 11.850 & 37.713 & $\mathbf{2}$ \\
\hline 6 & Ridho Adrian & 7.159 & 28.899 & 15.775 & $\mathbf{1}$ \\
\hline 7 & Yantonius Gulo & 50.292 & 45.844 & 30.647 & $\mathbf{3}$ \\
\hline 8 & Wijaya Avin Mandela Gea & 7.159 & 28.115 & 26.507 & $\mathbf{1}$ \\
\hline 9 & Nurkhofifah Nasution & 24.088 & 14.477 & 34.494 & $\mathbf{2}$ \\
\hline 10 & Mita Dewi Yanti Siregar & 36.637 & 15.432 & 33.821 & $\mathbf{2}$ \\
\hline
\end{tabular}




\begin{tabular}{|c|l|c|c|c|c|}
\hline No & Nama Calon Mahasiswa & dc1 & dc2 & Dc3 & Hasil \\
\hline 11 & Kartika & 27.681 & 21.840 & 12.579 & $\mathbf{3}$ \\
\hline 12 & Mario Valentino Batu Bara & 24.357 & 35.283 & 15.570 & $\mathbf{3}$ \\
\hline 13 & Boy Alfredo Silaban & 21.360 & 33.592 & 14.291 & $\mathbf{3}$ \\
\hline 14 & Suhaidi & 25.461 & 34.614 & 7.736 & $\mathbf{3}$ \\
\hline 15 & Muammar Nugraha Rozy Affan & 28.918 & 12.638 & 30.946 & $\mathbf{2}$ \\
\hline
\end{tabular}

Pada iterasi - 2, tidak ada perbedaan hasil clustering pada iterasi -1 dan iterasi -2. Oleh karena itu, maka proses berhenti. Berdasarkan perhitungan jarak dekat, maka maka calon mahasiswa baru dapat dikelompok sebagai berikut:

Tabel 6. Kelompok 1

\begin{tabular}{|l|l|}
\hline No. & Nama Calon Mahasiswa Baru \\
\hline 6 & Ridho Adrian \\
\hline 8 & Wijaya Avin Mandela Gea \\
\hline
\end{tabular}

Calon mahasiswa pada kelompok 1, berpotensi pada bidang umum

Tabel 7. Kelompok 2

\begin{tabular}{|l|l|}
\hline No. & Nama Calon Mahasiswa Baru \\
\hline 1 & Dwiki Fahizurrahman \\
\hline 2 & Jhonswardi Sianturi \\
\hline 4 & Anisa Suryani Rangkuti \\
\hline 5 & Habib Nasrullah Fisyih \\
\hline 9 & Nurkhofifah Nasution \\
\hline 10 & Mita Dewi Yanti Siregar \\
\hline 15 & Muammar Nugraha Rozy Affan \\
\hline
\end{tabular}

Calon mahasiswa pada kelompok 2, berpotensi pada bidang bahasa.

Tabel 8. Kelompok 3

\begin{tabular}{|l|l|}
\hline No. & Nama Calon Mahasiswa Baru \\
\hline 3 & Chairina Ridwan \\
\hline 7 & Yantonius Gulo \\
\hline 11 & Kartika \\
\hline 12 & Mario Valentino Batu Bara \\
\hline 13 & Boy Alfredo Silaban \\
\hline 14 & Suhaidi \\
\hline
\end{tabular}

Sedangkan mahasiswa pada kelompok 3, berpotensi pada bidang eksakta.

\section{KESIMPULAN}

Berdasarkan uraian diatas, maka kesimpulan dari penelitian ini adalah sebagai berikut:

a. Algoritma Clustering K-Means dapat diimplementasikan dalam pengelompokan calon mahasiswa baru yang berpotensi khususnya di STMIK Budi Darma.

b. Berdasarkan sampling data yang digunakan, data dapat dikelompokan kedalam 3(tiga) clustering. 
c. Dengan algoritma Clustering K-Means calon mahasiswa dikelompokkan kedalam 3(tiga) kelompok yaitu kelompok 1 calon mahasiswa yang bernomor urut 6 dan 8 dan borpotensi pada bidang bidang umum, kelompok 2 calon mahasiswa yang bernomor urut 1, 2, 4, 5, 9, 10, 15 dan berpotensi pada bidang bahasa, serta kelompok 3 calon mahasiswa yang bernomor urut 3, 7, 11, 12, 13, 14 dan berpotensi pada bidang eksakta.

d. Pengelompokan berdasarkan potensi yang dimiliki dapat mempermudah dosen dalam melaksanakan tindakan kelas.

\section{DAFTAR PUSTAKA}

[1] J. O. Ong, "Implementasi Algotritma K-means clustering untuk menentukan strategi marketing president university,” J. Ilm. Tek. Ind., vol. vol.12, no, no. juni, pp. 10-20, 2013.

[2] J. C. Rubio-romero et al., "Data Mining Menggunakan Algoritma K-Means Clustering Untuk Menentukan Strategi Promosi," Ind. Mark. Manag., vol. 1, no. 1, pp. 1-9, 2014.

[3] E. Buulolo, "Implementasi Algoritma Apriori Pada Sistem Persediaan Obat ( Studi Kasus: Apotik Rumah Sakit Estomihi Medan )," Pelita Inform. Budi Dharma, vol. 4, no. Agustus 2013, pp. 71-83, 2013.

[4] E. Buulolo, N. Silalahi, Fadlina, and R. Rahim, "C4.5 Algorithm To Predict the Impact of the Earthquake," Int. J. Eng. Res. Technol., vol. 6, no. 2, pp. 10-15, 2017.

[5] H. Aprilianto and E. Ramadhani, "Implementasi Metode K-Means Clustering untuk Pengelompokan Lulusan STMIK-Banjarbaru Berdasarkan Kompetensi,” Progresif, vol. 9, No.1, no. ISSN: 0216-3284, 2013.

[6] F. Nasari and S. Darma, "PENERAPAN K-MEANS CLUSTERING PADA DATA PENERIMAAN MAHASISWA BARU," in Seminar Nasional Teknologi Informasi dan Multimedia 2015, 2015, pp. 6-8. 